\title{
ВMJ Global Health Building the evidence base for global health policy: the need to strengthen institutional networks, geographical representation and global collaboration
}

\author{
Zsuzsanna Jakab, ${ }^{1}$ Duncan Selbie, ${ }^{2}$ Neil Squires, ${ }^{3}$ Saqif Mustafa (D) , ${ }^{1}$ \\ Sohel Saikat ${ }^{1}$
}

To cite: Jakab Z, Selbie D, Squires $\mathrm{N}$, et al. Building the evidence base for global health policy: the need to strengthen institutional networks, geographical representation and global collaboration. BMJ Global Health 2021;6:e006852. doi:10.1136/ bmjgh-2021-006852

Handling editor Seye Abimbola

- Additional supplemental material is published online only. To view, please visit the journal online (http://dx.doi.org/10. 1136/bmjgh-2021-006852).

Received 8 July 2021 Accepted 3 August 2021

Check for updates

(c) Author(s) (or their employer(s)) 2021. Re-use permitted under CC BY-NC. No commercial re-use. See rights and permissions. Published by BMJ.

${ }^{1}$ World Health Organization, Geneva, Switzerland

${ }^{2}$ International Association of National Public Health Institutes, Paris, France

${ }^{3}$ Global Public Health, Public Health England, London, UK

Correspondence to

Dr Sohel Saikat;

saikats@who.int

\section{ABSTRACT}

National public health institutes and WHO collaborating centres, and their global networks, are a key resource to support public health system strengthening with essential public health functions and generate evidence for health policy central to national health and socioeconomic development. The COVID-19 pandemic has laid bare global inequities in public health capacities, made urgent the need to examine sources of global knowledge and understand how to better invest in and use public health institutes and their capacities. This analysis paper incorporates experiences and perspectives from the WHO and International Association of National Public Health Institutes including the ongoing pandemic and work conducted in the UK-WHO 'Tackling Deadly Diseases in Africa Programme'. We acknowledge geographical disparities in public health capacities both within and across countries and regions, provide examples of novel ways of working for global health actors, and define the challenging environment in which public health authorities operate. We identify four incentives for all countries to invest in public health and strengthen institutions: (1) transparency and trust; (2) socioeconomic dividends; (3) collective health protection and (4) knowledge sharing and equity. By pursuing shared priorities; enabling voices from low-resource settings to be more equitably heard; facilitating collaboration and learning within and across regions, we articulate actionable next steps to develop and better harness public health institutes and international networks.

\section{INTRODUCTION}

In an early review of the $\mathrm{WHO}$ response to the COVID-19 pandemic, the WHO Independent Oversight and Advisory Committee recommended WHO make more robust use of its collaborating centres, expert networks and public health institutes to supplement its capacity for timely response to global health threats. ${ }^{1}$

In many countries, national public health institutes (NPHIs) and WHO collaborating

\section{Summary box}

- Currently, there is considerable disparity in the coverage of national public health institutes and capacity within and between WHO's six regions.

- The positioning of public health and related research in national policy and decision making, including during emergencies, is inadequate, ad hoc and reactive indicative of the variability in legislative and institutional set up supporting public health.

- Public health stewardship is operating with limited resources, which hinders their ability to rapidly generate and disseminate the evidence needed to inform and promote public health complementing the predominant focus on healthcare and emergency response.

- As health systems respond to and recover from COVID-19, countries should establish, reconfigure and strengthen national public health institutes and give greater prominence with adequate investment to public health in national policy and global agendas.

centres (WCCs) are a key resource linked to global networks, which can support public health system strengthening, the development of the essential public health functions (EPHFs) and generate and synthesise the evidence necessary for health policy. ${ }^{2} 3$ The emergence of COVID-19 has been a significant test of these global knowledge networks and a stimulus for greater collaboration to generate the evidence needed for an effective and equitable policy response. ${ }^{4}$ The pandemic has also laid bare global inequities in public health capacities both within and across countries ${ }^{56}$ making urgent the need to examine sources of global knowledge and understand how NPHIs and WCCs can be better used, particularly in under-resourced settings. $^{12}$ 
This paper highlights the role of NPHIs and WCCs on public health system strengthening and policy formation and presents evidence on the inequity in capacities and representation of public health expertise globally using examples drawn from a UK-WHO collaboration, the 'Tackling Deadly Diseases in Africa Programme' (TDDAP). (TDDAP was a UK Department for International Development (now Foreign, Commonwealth \& Development Office) funded three year (2017-2020) collaboration with WHO. Its objectives were to support WHO's work with 47 African Member States to develop robust, responsive and resilient health systems and enhance capacities for health security.) The challenges and opportunities for strengthening public health systems and better utilising existing networks are reviewed focusing on the network of NPHIs represented by the International Association of National Public Health Institutes (IANPHI) and on WCCs in order to identify new ways of working. The value proposition for increasing attention and investment in NPHIs and building EPHFs are considered, arguing impetus generated by lessons from COVID-19 should galvanise change.

\section{THE ROLE OF NATIONAL PUBLIC HEALTH INSTITUTES AND WHO COLLABORATING CENTRES}

EPHFs provide context for defining what NPHIs do and, on the basis of regional versions of EPHFs, IANPHI has developed a list of core NPHI functions. ${ }^{78}$ These include disease surveillance; disaster risk reduction; outbreak investigation and control; workforce development; health promotion; laboratory science; research and health information analysis to inform policy. ${ }^{2}$ EPHFs are provided through a range of organisations typically under the oversight of national Ministries of Health. NPHIs are often autonomous or semiautonomous units of Ministries of Health and their activities can be prescribed by law. ${ }^{79} 10$ They can be developed and used to better integrate and facilitate the delivery of EPHFs for public health system strengthening, encompassing health security and other public health services. ${ }^{9-13}$ When given the authority, NPHIs can be the focal point for inter-ministerial and multisectoral collaboration and information sharing and can play a central role in health policy formation..$^{1011} 13$

WCCs can be part of an NPHI, university, research institute or laboratory and support the delivery of WHO's priorities in health. ${ }^{14} 15$ In 1949, the Second World Health Assembly recommended that WHO, rather than developing its own research capacity, should 'assist, coordinate and make use of the activities of existing institutions'. ${ }^{16}$ This is an approach that WHO has followed by establishing links with academia and research institutes as well as NPHIs across a range of health disciplines, such as: health security; nursing; occupational health; mental health and chronic diseases. WCCs are not funded by WHO but bring mutual benefit-with WHO gaining access to and convening operational expertise to support delivery, research and policy development and host institutions enhancing their reputations through the WHO affiliation and extended networking.

\section{GEOGRAPHICAL DISPARITY IN PUBLIC HEALTH CAPACITIES}

In some countries with strong national public health systems, the mobilisation of expertise from a range of public health authorities at the national and subnational level is actively supporting the generation of evidence to inform the COVID-19 response. ${ }^{17}$ However, there are countries where public health institutional capacity remains nascent. IANPHI, which maps and establishes cooperation between NPHIs, with a mission to build NPHI capacity internationally, has established links with 94 countries and is reaching out to others as they consider establishing NPHIs. ${ }^{2}$

In 2019, as part of the WHO-UK TDDAP project, WHO conducted a literature review (see online supplemental appendix) and mapping to understand the nature and scale of NPHI and academic institute involvement in the development and delivery of EPHFs, focusing on the African continent. The results were consulted on with the WHO Africa Regional Office and shared through their engagement with WCCs in Africa and through academic partners and Ministries of Health.

The findings indicated that up to 15 countries in the WHO African region do not have a readily discernible or dedicated NPHI. There are countries in which NPHIs are in the process of being established such as Uganda and the Democratic Republic of Congo, with others being newly formed (at least five of Africa's 39 NPHIs were established during or after the West Africa Ebola outbreaks in 2014-2016 including Botswana's, Liberia's and Sierra Leone's). New NPHIs are likely to have less involvement across the full range of EPHFs and less of a role in public health systems strengthening compared with mature ones. ${ }^{12}$ African NPHIs' cited functions relate predominantly to health workforce training, surveillance and information systems with limited indicative activity in health financing, research and policy development.

The potential for NPHIs, academia and research institutes to equitably contribute to global health policy is hindered by disparities in the representation of WCCs by geographical location and country income group. Study of WHO's database on WCCs undertaken in 2019, highlighted that out of 822 WCCs based in 99 countries across all six WHO regions, only 35 are on the continent of Africa. By comparison, there are 80 in the USA, 66 in China, 58 in the UK, 57 in India and 48 in Australia (figure 1). ${ }^{14}$ One-third of all WCCs are located in the WHO European region, 24\% are in the Western Pacific Region, $22 \%$ are in the region of the Americas, $13 \%$ are in the South-East Asian region, 5\% in the Eastern Mediterranean region and only $3 \%$ in the African region. Nearly $80 \%$ of all WCCs are based in just 22 countries, 13 of which are high-income countries. ${ }^{14}$

Of the 35 WCCs on the continent of Africa, 14 are in South Africa, and 9 are in the WHO Eastern 


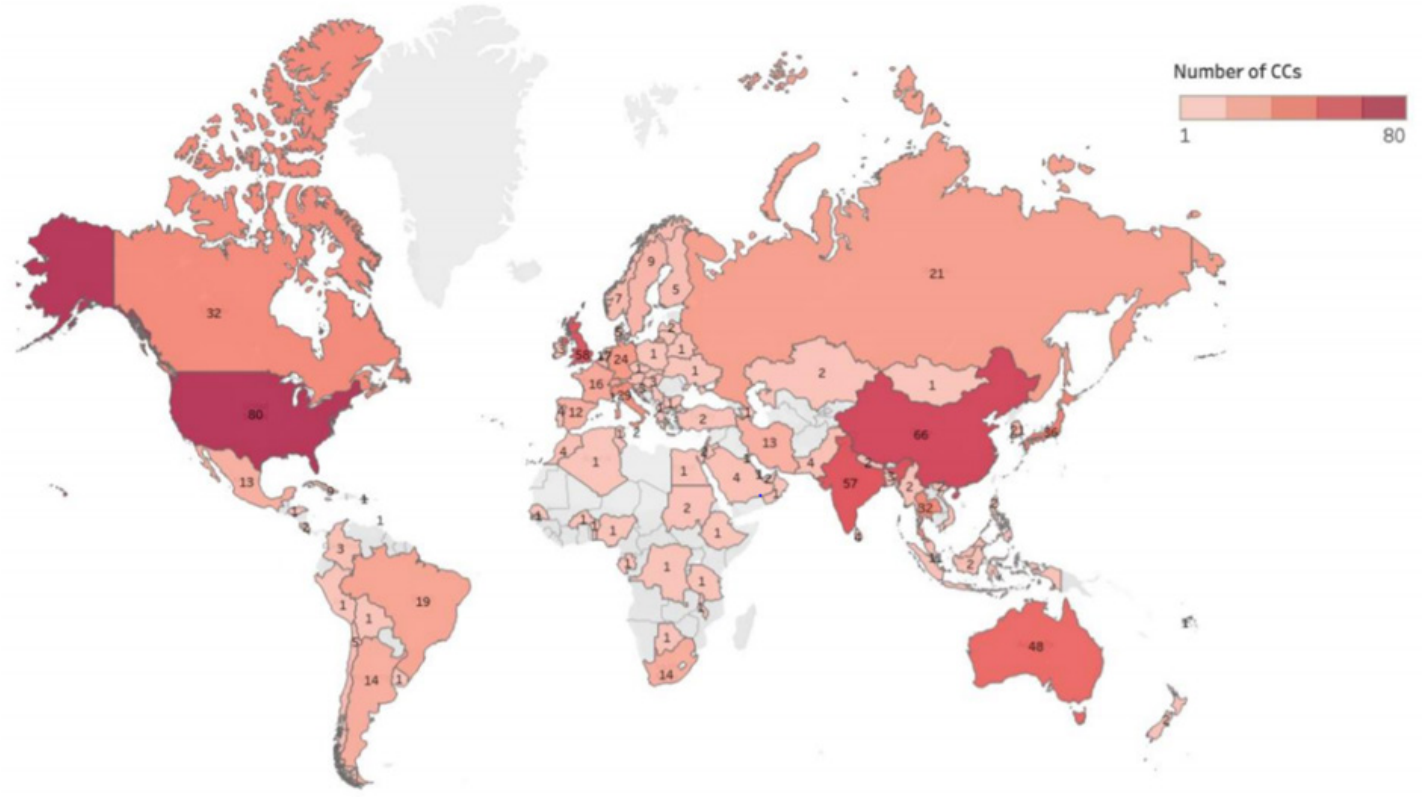

Figure 1 Global distribution of WHO collaborating centres (WCCs) (WCCs=WHO Collaborating Centres). WCC database, 2019. ${ }^{1420}$

Mediterranean region. Study of individual African countries' WCCs highlighted their greatest involvement to be in activities relating to workforce training and provided limited evidence of their participation in research and evidence generation to inform the policy development process. At the subnational level, empirical studies investigating the activities of African universities suggest that postgraduate courses in public health were not directly engaging in research activities, with the exception of a few larger public health schools. ${ }^{18}$ Recent cross-sectional survey data from 35 countries of the WHO African region indicated that only 15 countries had health research strategies, with lack of clarity between mandates of different institutions partly attributed to this. ${ }^{19}$

When heads of WCCs globally were surveyed as part of WHO's evaluation of its work with collaborating centres, the greatest challenge reported was a lack of resources $(57 \%) .^{20}$ The evaluation report acknowledges WCCs based in low-income and middle-income countries have distinct needs and require tailored technical support.

Taken together, there is clear evidence of public health actors in low resource settings, as exemplified in Africa, having a limited voice in contributing to the national and global knowledge pool and footprint in global health policy formulation.

\section{HOW CAN BILATERAL AND MULTILATERAL ACTORS FACILITATE PUBLIC HEALTH SYSTEM STRENGTHENING?}

Different countries are at different stages in developing their public health systems and NPHIs, and many are restructuring as a result of lessons learnt from COVID19. This presents challenges and opportunities for WHO in its global public health system leadership role and for IANPHI, in support of its global network of member institutions. The balance of responsibilities between different actors in the public health system face significant change as each nation reflects on its COVID-19 response.

Countries such as Finland and the USA, which established their NPHIs decades ago, operate from a position of strength which comes from an established track record, making them a significant resource for knowledge and experience exchange globally. Countries with NPHIs that have recently undergone or are undergoing restructuring, such as Canada, China and the UK, can share lessons of their reorganisations, increasing understanding of the rationale, benefits and potential pitfalls of change. ${ }^{21}$ Resource-rich NPHIs, such as the Robert Koch Institute in Germany, Fiocruz in Brazil and Public Health England, have expertise in delivering the EPHFs as well as in international collaboration for capacity building, which enhances their ability to offer peer to peer engagement in support of others. ${ }^{22}$ However, important learning between NPHIs will also come from exchanges between NPHIs that are newly formed or working in low-resource settings, where the ability to travel and exchange experience with neighbours and peers is severely limited by work demands, limited funds and flexibility to invest time collaborating with others. ${ }^{23}$

At the regional level, the European CDC's (Centre for Disease Prevention and Control) work is closely linked with that of NPHIs, Ministries of Health and public health research institutions within the European Union. This includes daily interaction with stakeholders through information exchange and sharing of analysis, guidance and technical assistance. The European CDC's role as a regional, apolitical, scientific and technical agency includes providing the European Commission, 
European Parliament and national health policy-makers with the evidence needed for health policy, and can serve to inform models of regional public health capacity building. The African Union's Africa CDC has made a commitment to promoting and strengthening functional $\mathrm{NPHIs}^{24}$ seeing them as critical for the implementation of the International Health Regulations (2005) which underpin global health security. ${ }^{25}$ Africa CDC also sees its role extending beyond health security and infectious disease control, with recent discussions on how the African Union can respond to the growing burden of noncommunicable diseases. Building public health capacity to deliver the full range of EPHF is important, recognising that public health systems need to address both communicable and non-communicable disease as well as acting to reduce the impact of the broader determinants of health. In a similar vein, the WHO European regional office has been working with IANPHI and the Association of Schools of Public Health in the European Region to develop competency-based public health training, intended to equip future public health leaders with a full range of competencies needed to address varied public health challenges. Competency-based training has been at the heart of the UK's public health system, recognising that leadership in public health requires more than just academic qualifications. The training encompasses a wider range of competencies which build leadership, management and diplomacy skills as well as skills in health promotion, disease prevention and health protection. ${ }^{26}$ Extending this approach globally has the potential to develop a global cadre of public health practitioners, trained to meet the needs of the organisations that will employ them and to be system leaders who can work across the business of government in order to address barriers to equity and act to address the broader determinants of health. Through such networks of networks, with Schools of Public Health working with National Institutes, with professional bodies and international agencies, lessons can also be transmitted from region to region. For example, the Association of Schools of Public Health in the Africa is beginning to adapt the European competency framework to their context. ${ }^{27}$

Collaborative multilateral international networks are also being used to strengthen EPHFs, however, there is scope for better utilisation of these and IANPHI and WHO are working together to ensure synergy between the bilateral and multilateral system strengthening they support. ${ }^{12022}$ All six WHO regional offices have undertaken consultations with their WCCs to better align technical work to WHO's global health objectives including public health system strengthening for universal health coverage and health security. ${ }^{20}$ The WHO and IANPHI, along with other key partners, are evolving their collaboration in support of developing NPHI and WCC public health capacity in under-resourced settings, including initial discussions on the use of IANPHI's peer-to-peer support approach. ${ }^{28}{ }^{29}$ WHO, IANPHI and partners can also advocate for strengthening of NPHIs and greater equity in global health including distribution of vaccines at high-level fora such as the World Health Assembly, G7 and G20. For example, in May 2021, IANPHI represented the interests of NPHI leaders at a G7 roundtable discussion on opportunities for greater collaboration on public health in the African region and emphasised the importance of G7 nations investing in NPHIs and the EPHFs. There has also been discussion between WHO's Deputy Director-General and the President of IANPHI, and other senior leadership to position the public health agenda in joint support to countries during ongoing and post-COVID-19 recovery efforts.

\section{Challenges and a new way forward}

The most significant challenge faced by NPHIs and WCCs is limited resources which hinder their capacity to rapidly generate and disseminate the evidence needed to inform policy. ${ }^{20}$ This is particularly prevalent in the low-income and middle-income country contexts, however, public health infrastructure in high-income countries also face resource challenges, particularly during health emergencies. ${ }^{30}$ Health spending and attention is overwhelmingly directed towards strengthening healthcare, often in a reactive manner on emergency response interventions, with limited investment in public health promotion, improvement and protection, and disease prevention capacities.

WCCs in high-income countries need to be able to internally justify delivering work in support of global health objectives to demonstrate that this is not diverting resource from domestic priorities. WCCs, therefore, tend to be concentrated in better resourced institutions, perpetuating inequity within high-income countries with WCC status often given to 'elite' status public health schools, from the Russel Group of universities in the UK and Ivy League schools in the US for example, who receive greater research funding and are therefore better placed to engage in national and global policy dialogue. ${ }^{31-33}$ Opportunities need to be explored to determine how these institutions can extend their support to less well-resourced institutions, particularly those in lowincome countries, which would make a commitment to addressing inequity a key part of gaining WCC status.

An important challenge is overcoming the current focus of individual NPHIs and WCCs on specific technical areas with limited coordination, gaps and overall coverage of the EPHFs nationally. Siloed attention and funding on health security, disease- and age-specific areas, although beneficial in terms of providing focus, requires careful planning and coordination to benefit health systems strengthening, in alignment with national priorities and national health research agendas. This requires strong stewardship capacity for public health within Ministries of Health and allied Ministries to avoid the development of fragmented health systems and can result in duplication and lack of sustainability. ${ }^{34}$

A new way of working will be required to overcome the challenges of tackling local, national and global public 
health threats with limited resources. Harnessing of the opportunities that widespread political and multisectoral attention COVID-19 has brought to public health will be needed if we are to take a more integrated approach to health system strengthening by bringing together actors within and outside the health sector and overcome nationalistic and isolationist policies.

Ministries of Health and NPHIs should have the operational capacity to build and deliver the EPHFs during both times of emergency, such as COVID-19, and periods of normalcy. Championing public health should not just be limited to periods of emergency response, building health system capacities for effective delivery of EPHFs requires sustainable long-term investment. Networks such as IANPHI and WCCs should be expanded in countries with low coverage and be better utilised by systematically collating and disseminating good practices and harvesting their use in evidence-based policymaking, irrespective of location and country income status. Current transfer of experiences and expertise in existing networks from North-to-South is beneficial but there is a need to bolster the direction of exchange from South-toSouth, South-to-North and North-to-North.

\section{VALUE PROPOSITION FOR INCREASED INVESTMENTS IN PUBLIC HEALTH INSTITUTES}

COVID-19 has reinforced our understanding that no one is safe unless everyone is safe. It also reconfirmed the need for integrated investment in healthcare and populationbased public health capacity development. There are several incentives for countries of all income groups to strengthen under resourced NPHIs and academic and research institutes and invest in EPHFs locally, nationally and globally: (1) transparency and trust, (2) socioeconomic dividends, (3) collective health protection and (4) knowledge sharing and equity.

\section{Transparency and trust}

Strong NPHIs and WCCs allow countries to take an evidence-based approach to policy-making. They enable countries to set, implement and address national public health priorities within and outside the traditional health sector. $^{91112}$ They can communicate complex, scientific messaging on public health matters to communities and populations on behalf of government authorities. They can enable a degree of transparency in the otherwise opaque policy making process. While COVID-19 has stressed the importance of public health capacity and communication in the context of infectious disease and health security, the benefits of public health system strengthening extend far beyond, for example, in tackling the rising incidence of noncommunicable diseases and mental health, antimicrobial resistance, occupational health, road traffic safety, food safety, environmental health and climate change. ${ }^{35}$ Aligning the national public health research agenda, priorities and policies with the direct and pressing needs of communities and populations builds trust in health services and authorities. In under-resourced settings, having a focal public health or research institute receiving external or donor funds can enable more efficient coordination, accountability mechanisms and use of resources aligned with public health priorities, which also contributes to transparency and building of trust. ${ }^{34}$

\section{Socioeconomic dividends}

The health of populations is key to maintaining social and economic growth and chronic neglect of public health systems can have a devastating impact on the domestic and global economy. ${ }^{36}$ The policy response to COVID-19 globally has required lockdowns, social/physical distancing, restrictions in travel and trade, school closures, and shutting down of whole industries. These have disproportionately impacted the poor and many have lost their jobs, adding pressures on governments and increasing social insecurity with a looming financial and debt crisis. ${ }^{37} 38$ Greater attention and investments in EPHFs and public health institutes proportionate to that of healthcare systems could reduce pressure on health facilities and save more lives at reduced cost. For example, by effectively tackling small emergencies before they become large-scale events. ${ }^{30}$ COVID-19 and prior experiences and evidence demonstrates that it is in the socioeconomic interest of all countries to invest in public health system strengthening.

\section{Collective health protection}

Public health threats do not respect national borders. Weak public health systems abroad therefore pose risks to domestic populations. Since the 2014-2015 Ebola outbreaks and the 2016 Zika outbreaks, findings of a number of high-level reviews of global responses to infectious disease outbreaks have made it clear that there is a need for a more joined up approach between health system strengthening and emergency preparedness and response efforts. ${ }^{39}$ Investments in NPHIs and national capacity to delivery EPHFs can enable this more integrated approach, with enhanced cross-border cooperation in data sharing and resources helping ensure the benefits of investments in public health systems in one country yield benefit to the wider region and globally.

\section{Knowledge sharing and equity}

COVID-19 has exposed the myth that any one country has all the solutions to tackle global health challenges. It has confirmed the need to give a greater, more equitable voice to the global south and to better harness networks for multidirectional learning. WCCs, expert networks and NPHIs in the global south offer a largely untapped and rich source of evidence and capacity that should be given greater attention. For example, as early as February 2020, during the reporting of the first cases of COVID-19, the African Union's Africa CDC with WHO AFRO led efforts to pool whole-of-society, whole-of-government resources, quickly involving national and international public and private stakeholders such as the 
African Union Development Agency and setting up working groups comprising regional partners and NPHIs. ${ }^{40} \mathrm{~A}$ regionwide health crisis response plan was drawn up taking a health systems-wide approach and seeking to tackle problems at the community level on key issues such as health service delivery, health workforce, research and development and local innovation and manufacturing capacity. Following this, African countries rapidly implemented public health and social measures to contain outbreaks and these are likely to have slowed the transmission of the virus. Overall, the number of cases in Africa has been lower than initial forecasts, although further data is needed to ascertain the coverage and effectiveness of existing surveillance and diagnosis. NPHIs globally can benefit from sharing lessons in, for example, coordinating COVID-19 response at local, national and regional levels. ${ }^{41}$ This, however, requires sustainable investments geared towards building long-term national institutional capacities to deliver the EPHFs and giving hitherto underrepresented public health actors a more equitable voice in global health discourse and policy.

\section{CONCLUSION}

WHO is committed to making more robust use of its collaborating centres, networks and NPHIs in global health including capacity development of currently underresourced and represented partners. IANPHI has launched a strategy for the period 2021-2025 which commits to build public health capacity and capabilities worldwide. IANPHI's vision, shared by $\mathrm{WHO}$, is of a global community of interdependent and trusted NPHIs acting as scientific advisors to governments, working together to protect and improve the public's health and build a more equitable world. In order to achieve this ambition, we make the following recommendations:

NPHIs and associated public health infrastructure, in generating the evidence to inform policy-making, should increasingly enable voices from low resource settings to be more equitably heard. This requires global health policy actors to:

- Pursue shared priorities through coordination, collaboration and knowledge sharing to build more resilient public health systems.

- Develop tools and resources to contextualise and operationalise the EPHFs integral to health systems strengthening and health security efforts.

- Invest and collaborate with national authorities (Ministries of Health) to establish and strengthen NPHIs and promote the EPHFs.

Learning from regional and local best practices, national and global health authorities can:

- Strengthen or establish regional hubs or 'centres of excellence' among NPHIs and WCCs to increase knowledge translation for action.

- Enhance academic partnerships between countries through connecting schools of public health and public health programmes.
- Bolster networks of NPHIs supported by IANPHI that also connects with international structures and professional groups.

- Support twinning partnerships and peer-to-peer capacity building between NPHIs.

NPHIs should be fit-for-purpose to meet public health challenges and have sufficient autonomy to build credibility and trust with the population. This will require national authorities to:

- Legislate to support NPHI development.

- Create an enabling environment for research, innovation and learning and application of lessons to policies, planning, implementation and monitoring.

- Permit NPHIs, academic and research institutes a degree of operational autonomy on technical matters, allowing them to speak to the evidence to inform policy decisions.

As the world's health systems and economies grapple with post-COVID-19 recovery, there is an opportunity to invest in health systems transformation to tackle the ongoing and emerging threats to public health and economic security. Countries should establish, reconfigure and develop their NPHIs through:

- Sustained advocacy and political will to make public health capacity development part of national and global economic and health sector recovery planning.

- Funding bodies and development partners encouragement of national authorities to institutionalise the public health agenda within state architecture.

- Greater prominence for public health in domestic and global funding.

Twitter Saqif Mustafa @saqifm

Acknowledgements This work was partly undertaken within the context of the UK Department for International Development (DFID—now part of the FCDO) funded WHO Tackling Deadly Diseases in Africa Programme (TDDAP), with the aim of strengthening the collaboration between the health system and health security clusters to promote health security and build resilient health systems. Appreciation goes to colleagues in WHO: Zandile Zibwowa, Redda Seifeldin, Geraldine McDarby, Yu Zhang, Pascal Abie, Humphrey Karamagi, Prosper Tumusiime, Benson Droti, Rajesh Sreedharan, Ed Kelley, Ruediger Krech, Gerard Schmets and Soumya Swaminathan; Sante Publique France: Anne-Catherine Viso; and the University of Edinburgh: Mark Hellowell.

Contributors NS, ZJ and DS conceived this analysis article. SM, NS and SS curated the evidence and perspectives underpinning this article and drafted the manuscript. ZJ and DS reviewed and edited the manuscript. SS coordinated the overall process. All authors approved the final manuscript.

Funding This article was developed as part of WHO and IANPHI's core work.

Map disclaimer The inclusion of any map (including the depiction of any boundaries therein), or of any geographic or locational reference, does not imply the expression of any opinion whatsoever on the part of BMJ concerning the legal status of any country, territory, jurisdiction or area or of its authorities. Any such expression remains solely that of the relevant source and is not endorsed by BMJ. Maps are provided without any warranty of any kind, either express or implied.

Competing interests None declared.

Patient consent for publication Not required.

Provenance and peer review Not commissioned; externally peer reviewed.

Data availability statement Data are available upon reasonable request.

Supplemental material This content has been supplied by the author(s). It has not been vetted by BMJ Publishing Group Limited (BMJ) and may not have been peer-reviewed. Any opinions or recommendations discussed are solely those 
of the author(s) and are not endorsed by BMJ. BMJ disclaims all liability and responsibility arising from any reliance placed on the content. Where the content includes any translated material, BMJ does not warrant the accuracy and reliability of the translations (including but not limited to local regulations, clinical guidelines, terminology, drug names and drug dosages), and is not responsible for any error and/or omissions arising from translation and adaptation or otherwise.

Open access This is an open access article distributed in accordance with the Creative Commons Attribution Non Commercial (CC BY-NC 4.0) license, which permits others to distribute, remix, adapt, build upon this work non-commercially, and license their derivative works on different terms, provided the original work is properly cited, appropriate credit is given, any changes made indicated, and the use is non-commercial. See: http://creativecommons.org/licenses/by-nc/4.0/.

\section{ORCID iD}

Saqif Mustafa http://orcid.org/0000-0002-2034-9387

\section{REFERENCES}

1 Independent Oversight and Advisory Committee for the WHO Health Emergencies Programme. Interim report on WHO's response to COVID-19 January-April 2020, 2020. Available: https://www.who. int/about/who_reform/emergency-capacities/oversight-committee/ IOAC-interim-report-on-COVID-19.pdf?ua=1 [Accessed Jun 2021]

2 IANPHI. Progress report, 2020. Available: https://www.ianphi.org/_ includes/documents/sections/tools-resources/progress-reports/ 2020-ianphi-progress-report.pdf [Accessed June 2021].

3 Bergh A, Desenclos JC, Forland F. National public health Institutes collaborate with who to promote global health security. In: World health organisation Weekly epidemiological record. 94, 2019.

4 Alliance for health policy and systems research. bringing together evidence to tackle COVID-19, 2020. Available: https://www.who.int/ alliance-hpsr/news/2020/bringing-evidence-together-for-covid-19/ en/ [Accessed Jun 2021].

5 WHO. WHO Director-General's closing remarks at the World Health Assembly, 2020. Available: https://www.who.int/director-general/ speeches/detail/who-director-general-s-closing-remarks-at-theworld-health-assembly-13-november-2020 [Accessed Jun 2021]

6 Maani N, Galea S. COVID-19 and Underinvestment in the public health infrastructure of the United States. Milbank Q 2020;98:250259.

7 IANPHI. Framework for the creation and development of national public health Institutes, IANPHI Folio, 2007. Available: https://ianphi. org/_includes/documents/sections/tools-resources/all-frameworks/ frameworkfornphi.pdf [Accessed Jun 2021].

8 PAHO. Public health in the Americas: conceptual renewal, performance assessment, and bases for action, 2002. Available: https://iris.paho.org/bitstream/handle/10665.2/2748/9275115893. pdf [Accessed Jun 2021].

9 Adigun L, Dusenbury C, Schoub BD. Public health in Africa--the role of national public health institutes. S Afr Med J 2007;97:1036-9.

10 Africa CDC. Providing a legal framework for a national public health Institute (NPHI). Addis Ababa, 2017. Available: https://africacdc.org/ download/providing-a-legal-framework-for-a-national-public-healthinstitute-nphi/ [Accessed Jun 2021].

11 Koplan JP, Dusenbury C, Jousilahti P, et al. The role of national public health Institutes in health infrastructure development. BMJ 2007;335:834-5

12 Bloland P, Simone P, Burkholder B, et al. The role of public health institutions in global health system strengthening efforts: the US CDC's perspective. PLoS Med 2012;9:e1001199.

13 Khan MS, Dar O, Erondu NA, et al. Using critical information to strengthen pandemic preparedness: the role of national public health agencies. BMJ Glob Health 2020;5:e002830.

14 WHO. Who collaborating centres database, 2019. Available: https:// www.who.int/collaboratingcentres/database/en/ [Accessed Jun 2021].

15 Rashidian A, Mandil A, ElFeky S, et al. Who collaborating centres in the eastern Mediterranean region: an agenda for action and improvement (editorial). East Mediterr Health J 2019;24:1035-7.

16 WHO. Collaborating centres fact sheet, 2016. Available: https:// www.who.int/docs/default-source/documents/about-us/ factsheetwhocc2018.pdf?sfvrsn=8c7166ee_2 [Accessed Jun 2021].

17 National Network of Public Health Institutes. COVID-19 response, recovery, and resilience, 2021. Available: https://covid.nnphi.org/ [Accessed Jun 2021].

18 ljsselmuiden CB, Nchinda TC, Duale S, et al. Mapping Africa's advanced public health education capacity: the AfriHealth project. Bull World Health Organ 2007;85:914-22.
19 Nabyonga-Orem J, Asamani JA, Makanga M. The state of health research governance in Africa: what do we know and how can we improve? Health Res Policy Syst 2021;19:11.

20 WHO. Evaluation of WHO's work with Collaborating Centres, Volume 1: Report, 2002. Available: https://www.who.int/publications/m/item/ evaluation-of-who-s-work-with-collaborating-centres-volume-1report [Accessed Jun 2021].

21 Frieden TR, Koplan JP. Stronger national public health Institutes for global health. Lancet 2010;376:1721-2

22 Verrecchia R, Dar O, Mohamed-Ahmed O, et al. Building operational public health capacity through collaborative networks of national public health Institutes. BMJ Glob Health 2019;4:e001868.

23 US CDC. Strengthening national public health Institutes globally. global health protection and security, 2020. Available: https://www. cdc.gov/globalhealth/healthprotection/fieldupdates/winter-2016/ strengthen-nphi-globally.html [Accessed Jun 2021].

24 Africa CDC. Strengthening and establishing national public health Institutes as part of a network of the Africa centres for disease control and prevention, 2018. Available: https://africacdc.org/ download/strengthening-and-establishing-national-public-healthinstitutes-as-part-of-a-network-of-the-africa-centres-for-diseasecontrol-and-prevention/ [Accessed Jun 2021].

25 WHO. International health regulations (2005) third edition, 2016. Available: https://www.who.int/ihr/publications/9789241580496/en/ [Accessed Jun 2021].

26 Foldspang A, Birt C, Otok R. ASPHER's European List of Core Competences for the Public Health Professional. Scand J Public Health 2018;46:1-52.

27 Association of Schools of Public Health in Africa. Communiqué from 2018 ASPHA conference, 2018. Available: https://asphaafrica.net/ communique-2018-aspha-conference/

28 WHO. Establishing national public health Institutes through mergers - what does it take? joint who regional office for Europe and international association of national public health Institutes technical seminar, 2018. Available: https://www.euro.who.int/_data/assets/ pdf_file/0020/383303/nat-health-institutes-eng.pdf [Accessed Jun 2021].

29 Bergh A, Desenclos JC, Forland F. National public health Institutes collaborate with who to promote global health security. In: World Health Organisation Weekly epidemiological record. 94, 2019.

$30 \mathrm{WHO}$. The case for investing in public health, 2014. Available: https://apps.who.int/iris/bitstream/handle/10665/170471/CaseInvesting-Public-Health.pdf [Accessed Jun 2021].

31 Gotham D, Meldrum J, Nageshwaran V, et al. Global health equity in United Kingdom University research: a landscape of current policies and practices. Health Res Policy Syst 2016;14:76.

32 Nature. Key COVID research hit by cut to UK foreign-aid budget, 2021. Available: https://www.nature.com/articles/d41586-02101134-4 [Accessed Jun 2021]

33 Buse K, Hawkes S. The government must urgently reconsider UK research and innovation funding cuts. The BMJ opinion, 2021. Available: https://blogs.bmj.com/bmj/2021/03/17/the-governmentmust-urgently-reconsider-uk-research-and-innovation-funding-cuts/ [Accessed Jun 2021].

34 Jamison DT. Investing in health. In: Jamison DT, Breman JG, Measham AR, et al, eds. Disease control priorities in developing countries. 2 edn. New York: Oxford University Press,, 2006.

35 Dahlgren G, Whitehead M. European strategies for tackling social inequities in health: levelling up, part 2. Copenhagen: WHO Regional Office for Europe, 2007.

36 World Bank. World development report 1993: investing in health, 1993. Available: https://openknowledge.worldbank.org/handle/ 10986/5976 [Accessed Jun 2021].

37 Reinhart C. The quiet financial crisis. world bank blogs, 2021. Available: https://blogs.worldbank.org/developmenttalk/quietfinancial-crisis [Accessed Jun 2021].

38 Nicola M, Alsafi Z, Sohrabi C, et al. The socio-economic implications of the coronavirus pandemic (COVID-19): a review. Int J Surg 2020;78:185-93.

39 Kluge H, Martín-Moreno JM, Emiroglu N, et al. Strengthening global health security by embedding the International health regulations requirements into National health systems. BMJ Glob Health 2018;3:e000656.

40 The Africa Report. Africa: lessons learned so far from the COVID-19 pandemic. learning curve, 2020. Available: https://www. theafricareport.com/48729/africa-lessons-learned-so-far-from-thecovid-19-pandemic/ [Accessed Jun 2021].

41 Nkengasong JN, Mankoula W. Looming threat of COVID-19 infection in Africa: act collectively, and fast. Lancet 2020;395:841-2. 